\title{
The social media intervention for lower back pain education study (SMILE): a protocol for a randomized trial to reduce occupational low back pain in nursing professionals
}

Seyedeh Somayeh Kazemi ( $\sim$ somayehkazemi@modares.ac.ir)

Tarbiat Modares University https://orcid.org/0000-0001-9650-4569

Sedigheh-Sadat Tavafian

Tarbiat Modares University Faculty of Medical Sciences

Ali Montazeri

Iranian Institute for Health Sciences Research

Study protocol

Keywords: Occupational low back pain, Social media, Risk behavior, Disability, Quality of life

Posted Date: July 31st, 2019

DOl: https://doi.org/10.21203/rs.2.12199/v1

License: (c) (i) This work is licensed under a Creative Commons Attribution 4.0 International License.

Read Full License 


\section{Abstract}

Background Low back pain in nursing profession remains an important health issue. This study aims to assess whether a theory based interactive social media intervention could change job-related risk behaviors among nursing personnel. Methods This is a community-randomized controlled trial. Three settings of hospitals will randomly be assigned to the study arms: Intervention setting 1 receiving an inperson educational package; intervention setting 2 receiving the same material a web-based; and a control setting receiving nothing. The intervention would contain materials related to occupational risk behaviors and will try to promote the knowledge, attitude, skill, and self-efficacy of nurses on low back pain preventive behaviors. The primary outcome will be reduction in low back pain. The study also will assess whether the intervention could reduce pain-related disability and improve the quality of life. Discussion Occupational low back pain among nurses could adversely affect both patients and nurses' health. This study is an attempt to see if social media could play a role to guide the development and implementation of future interventions.

\section{Background}

Work-related musculoskeletal disorders (WMSDs) are estimated to be the most common and frequent of all occupational diseases (1). Also, they are the most important factor in losing time and damage to the workforce (2). Musculoskeletal disorders when are created people have an inappropriate physical condition while doing their jobs and tasks, causing pain in muscle and bone such as pain in the waist, neck, shoulder, elbow, wrists, Arms, hands and also organic lesions in some areas and organs (3).

Musculoskeletal disorders account for $7 \%$ of all diseases in the community; of which low back pain is one of the most prevalent disorders (4). Low back pain (LBP) is a common, recurrent and costly health problem worldwide (5). Low back pain affects between 51 and $90 \%$ of people at some point during their lifetime $(6,7)$. It has been evidenced that low back pain is one of the main reasons for seeking medical care $(8,9)$. It causes a massive medical and economic load on individuals, families, communities, industry, and governments (10-12).

The prevalence of low back pain is higher in some professions than in others (13). For instance, nursing professions are particularly experiencing a higher risk of low back pain and it accounts for $60 \%$ of the reported occupational disorders this population (14-16). Nursing has been recognized between the top professions at risk of low back pain (17), with low back pain rates exceeding those employed in heavy industry $(18,19)$. The year prevalence of low back pain in nurses has a mean of $70 \%(20-22)$ and the lifetime prevalence ranges from 35 to $80 \%(17,23-25)$. Recurrence rates of low back pain in nurses exceed $70 \%(26)$.

Low back pain in the nursing profession occur for several reasons including the nature of nursing care, patient mobility, long-standing, rotational movements, and repeated bending $(27,28)$. Even those who are working in emergency departments and intensive-care units are likely to suffer more from low back pain 
due to their specific working conditions (27). The impact of low back pain for nurses is large and includes work absenteeism, increased risk of chronicity, associated personal and economic costs, reduced nursing workforce efficiency, disability and decreased quality of life (17).

There are myriad factors have been identified for low back pain. Biomechanical risk factors such as physical load, force, frequency, vibration, bending, twisting, lifting, pushing/pulling, carrying, heavy physical work, posture. Psychosocial risk factors may affect a workers' psychological response to their work and influence the risk of low back disorders. For example, the mental workload, job stress, job satisfaction, social relations, job security, job demands, organizational level. Individual or personal risk factors such as age, gender, Body Mass Index (BMI), family history, genetics, smoking, physical activity, work experience (29). Although several factors play a role for low back pain in nurses, one of the most important reasons for low back pain due to occupation among nurses are behavioral factors $(30,31)$. In other words, it is argued that if nursing professions could take care of their behaviors during working hours then it would be possible to reduce or lessen their pain and suffering.

It is argued that the main barriers to nurse education are time constraint, shortness of classrooms in hospitals, several job commitments, and the costs. Indeed, to overcome these limitations we decided to use an interactive social media intervention. The use of social media interventions is increasingly becoming popular in public health and a number of studies showed that they were promising platform for promoting healthy behaviors especially when they were theory driven.

(32-34). Several studies indicate interventions that were strongly based in theory had a greater impact than those that were not (35). Thus, we decided to indicate behavioral factors that cause low back pain among nurses, design and develop an appropriate intervention based on the PRECEDE model (Predisposing, Reinforcing and Enabling Constructs in Educational/Environmental Diagnosis and Evaluation), and finally implement the intervention.

The PRECEDE is part of the PRECEDE-PROCEED (Policy, Regulatory and Organizational Constructs in Educational and Environmental Development) model and it is the most popular and commonly used health education planning model (36). As shown in Figure 1, a behavior can be influenced by predisposing, reinforcing, and enabling factors and thus an educational intervention or program based on the PRECEDE model seeks to identify these three factors and then if necessary make changes to predisposing factors (including knowledge, attitudes, beliefs and values), reinforcing factors (including attitudes and behaviors among those who are involved), and enabling factors (including access to resources, availability of health services, policies and legislation, and existing regulations, and behavioral skills that affect the adoption of a health behavior). Therefore, the reason for using this model to develop an interactive social media intervention for the prevention of low back pain is mostly comes from the multidimensional nature of job-related low back pain. In fact, this study tries to find out predisposing, reinforcing and enabling factors that can be applied to a program in the workplace in order to reduce low back pain among nursing professions. Another important reason for using the PRECEDE model is the unique ability to use it in designing and implementing educational interventions in the work environment. 
This is why the model has been the foundation of many health education and health interventions in the past three decades (36).

Several studies exist that examine the effectiveness of different educational interventions in this population (37-41). For instance, a study reported that stretching exercises in nurses with low back pain resulted in significant lower pain scores at follow-up compared to the control group (41). However, a recent systematic review of the literature on the efficacy of interventions for low back pain in nurses concluded that 'at present there is no strong evidence of efficacy for any intervention in preventing or treating low back pain in nurses. The authors recommended that it might be worth exploring high quality individualized interventions (17). Yet, many health behavior change websites are not theory driven and fail to incorporate proven, evidence-based approaches. A study by Evers et al. (2003) found that of 37 public health behavior change sites, few were theory driven or used evidence-based approaches (42).

The overall aim of this study is to develop and evaluate a theory based interactive social media intervention in order to reduce occupational low back pain in nurses working in teaching hospitals.

\section{Methods/ Design}

\section{Study overview}

This study consists of three phases. An overview of the different phases containing aims, methods and participants are depicted in Table 1.

\section{Aim}

The overall aim of this study is to develop and evaluate a theory based interactive social media intervention in order to reduce occupational low back pain in nurses working in teaching hospitals.

\section{Trial design}

This is a community-randomized controlled trial. The study will conduct in three hospitals. First, we will provide a list of all hospitals, and three hospitals will select randomly. Then selected hospitals allocated randomly by Roll of a dice to two intervention settings and one control setting. The intervention settings will receive educational programs while the control setting will receive nothing. Participants will be assessed at three points in time: at the baseline, three and six months follow up. The study procedure from enrollment through follow up data collection and analysis are shown in Figure 2.

\section{Study setting}

The study setting will be hospitals affiliated to Mazandaran University of Medical Sciences. 


\section{Participants}

The participants are nurses working in hospitals affiliated to Mazandaran University of Medical Sciences.

\section{Inclusion criteria}
a) Female,
b) $25-50$ years' old,
c) The desire of nurses to participate,
d) Having occupational low back pain,
e) Having access to Internet,
h) Having skills to work with Internet and mobile.

\section{Exclusion criteria}

a) Having any illness or problems that prevent a person from participating in the study and exercise for any reasons,

b) Being pregnant,

c) Having a pathological low back pain,

d) A prescription medication for low back pain.

\section{Intervention}

The main aim of this study was low back pain reduction. Thus, we will identify the individual and environmental factors affecting the back pain. For recognizing risk factors, and effective factors in promoting the health of the low back and design intervention, we will use the PRECEDE-PROCEED model. The findings of this phase will be obtained through semi-structured interviews.

On based the Educational and ecological assessment phase, we can determine factors that, if modified, would be most likely to result in behavior change and to sustain this change process. These factors are generally classified as predisposing, enabling, and reinforcing factors (36). According to administrative and policy assessment phase, we will identify resources, organizational barriers and facilitators, and policies for intervention implementation and sustainability (43). 
The educational content will include:

- Occupation low back pain and causes,

- The role of human and environmental factors affecting low back pain

- Stressors in the workplace, impact on back pain and stress management techniques

- Communicate effectively.

- Reinforcing and enabling factors affecting the health-promoting behaviors of the low back

- Ergonomic and Correct position of the spine in daily work

- Stretching exercises to increase flexibility

- Strengthening exercises to increase muscle strength

This educational material will be evidence-based and elaborated using understandable language and different formats, including pictures, video and 2 - 3D animation. The nurses will be able to contact a researcher by email, call and website. Furthermore, to reinforce nurses' motivation and participation, encouraging certificate (for annual evaluation) will implement.

The intervention setting 1 will receive the intervention via in-person education. They will receive education content in two sessions and 60 minutes per session and through group discussions, role-playing, questions-answers, lectures, educational films and, animations.

The intervention setting 2 will receive the intervention via a web site. They will receive training on how to use the site and they will be monitored by the main investigator. The content of the education will upload to the site in two days and at a specified time, such as the In-person intervention hospital. The content of intervention will be similar to setting one. Both of the intervention settings will receive a weekly reminder during the study period.

The control setting will receive nothing. However, after completion of the study the control group will receive one of the interventions based on their interest.

\section{Outcomes}

\section{Primary outcomes}

The primary outcome will be, reduced lower back pain. Lower back pain reduction will be assessed by using a VAS questionnaire. 


\section{Secondary outcomes}

Secondary outcomes will include reduced pain-related disability and increased quality of life.

\section{Data collection}

Data collection instrument will the standard questionnaire contained Visual Analog Scale, The Quebec Back Pain Disability Scale, Health Survey SF-36 and self-design questionnaire. The questionnaires will complete by nurses in 3 points time; before intervention, 3 months and 6 months after intervention. The questionnaires will nameless to participation's confidence towards the intervention.

The low back pain visual analog scale (VAS) has been widely used for measuring pain (44). Operationally a VAS is usually a horizontal line, $100 \mathrm{~mm}$ in length, anchored by word descriptors at each end, from none to an extreme amount of pain (none, mild, moderate and severe) (45). The validity and reliability of this scale have been repeatedly confirmed (46-48).

Reduced pain-related disability will be assessed by using the Quebec Back Pain Disability Scale (QBPDS) and increased quality of life will be assessed by using the Short Form Health Survey (SF-36) and at three points in time: at the baseline, three and six months after the intervention.

The Quebec Back Pain Disability Scale (QBPDS) is a 20-item self-administered instrument designed to assess the level of functional disability in individuals with back pain. Each item is rated on a 5-point Likert scale ranging from 0 to 5 giving a total score of 20 to 100 . Higher scores indicate greater disability (49). The validity and reliability of the Iranian version of the questionnaire are confirmed elsewhere (50).

The Short Form Health Survey (SF-36) is a 36-item questionnaire that measures eight dimensions of health status including physical functioning (10-item), role physical (4-item), bodily pain (2-item), general health (5-item), vitality (4-item), social functioning (2-item), role emotional (3-item) and mental health (5item) (51). The psychometric properties of the Iranian version of the questionnaire are well documented (52).

\section{Other variables}

Other variables also will be measured, including knowledge, attitude, self-efficacy, reinforcing factor, enabling factor and behavior (by self-design questionnaire). The self-designed questionnaire will design of 30 items and six components. Components will include knowledge, attitude, self-efficacy, reinforcing factor, enabling factor and behavior. Items with the Likert spectrum will be five parts. Its validity and reliability will be calculated.

\section{Sample size}


One hundred and eighty nurses working in hospitals affiliated to Mazandaran University of Medical Sciences who are eligible to enter into the study will be recruited. The sample size including $10 \%$ drop, 60 people are estimated for each study group in order to detect at least 20 percent differences in the primary outcome between intervention and control groups. As such the study would have a power of $80 \%$ at $5 \%$ significant level.

\section{Randomization}

First, we will provide a list of all hospitals from Mazandaran University of Medical Sciences. The name of hospitals will write on the card and placed in the box. Then the cards will blend and select 3 cards one after another. Then selected hospitals will allocate to intervention and control setting based on Roll of a dice (two hospitals as intervention settings and one hospital as the control setting). That way the numbers 1 and 2 will for the intervention setting 1, numbers 3 and 4 for the intervention setting 2 and the numbers 5 and 6 for the control setting.

In each hospital, participants will select based on the random number table and staff ID. We will label the staff ID. Then, we will select the starting point on the table and will be continued until the number of samples is completed.

\section{Implementation}

The researcher will generate the random allocation sequence and will enroll participants, then will assign participants to interventions.

\section{Blinding}

This study will be Single blind and participants will not be informed about setting allocation.

\section{Statistical analysis}

The quantitative data will be analyzed using SPSS V.23 (and if necessary, AMOS software). Descriptive statistics will include frequencies, means, and standard deviations. The Kolmogorov-Smirnov test will be used to check the normal distribution of data.

Between three groups the primary and secondary outcomes will assess using One Way ANOVA, Post-hoc (LSD) for determining the mean differences between which group. Also, for each group, we can use from ANOVA with a repeated measure for assessing the specific variable in three-time points. Continuous outcomes measured at the baseline and the third month will assess using baseline-adjusted ANCONA in the third month. For each group, continuous outcomes measured in the third month only will assess 
using paired-sample t-tests. Then the six-month outcomes will analyze and compare with the baseline and the third-month outcomes.

Sensitivity analysis for the primary outcome analysis used linear regression models adjusting for baseline prognostic variables, BMI, working hours, smoking, long-standing, heavy lifting, patient displacement, frequent bending and stress at the workplace.

For analysis assessing the correlation between demographic variables, using Correlation Tests (Pearson for parametric data and Spearman or Kendall for nonparametric data) and Chi-square test.

\section{Ethics}

The ethics committee of Tarbiat Modares University approved the study. All participants will ask for permission and completing the informed consent prior to the study commence.

\section{Discussion}

One of the features of this study is to pay attention to the promotion of health in the workplace. This study will investigate the efficacy of interventions for the reduction of low back pain in nurses. The main framework of this study will be the theory-driven and evidence-based approach to develop an interactive social media intervention for nurses. Moreover, we will execute the In-person intervention. Then we will compare the result of two education methods. Finally, this study will achieve the result of intervention based on interactive social media according to the workload and multiple shifts in the hospitals.

\section{Strengths and limitations:}

Strengths of this study include the community randomized controlled study design and that the study will be designed and implemented according to specific planning. The interactive social media will provide flexibility and convenience for users, supporting adherence to the program. Also, this study will compare two different educational methods but the same content.

One of the concerns will be that participants will not be assessed by a clinician and LBP will commonly be diagnosed through self-report. A second concern, during the course some participants might use pain relief medications which will affect the outcome of the study.

One of the strengths and weaknesses of the study is the 12-month follow-up that brings two concepts: 1 . Will education interventions be maintained long-time?

2. Or in the long-time, its effect will be paled?

\section{Trial status}


IRCT registration number: IRCT20170313033054N2

Registration date: $2018-02-25$

Recruitment start date: $2018-03-21$

Recruitment end date: $2018-05-19$

\section{List Of Abbreviations}

SMILE: Social Media Intervention for Lower back pain Education

WMSDs: Work-related musculoskeletal disorders

LBP: Low back pain

BMl: Body Mass Index

PRECEDE: Predisposing, Reinforcing and Enabling Constructs in Educational/Environmental Diagnosis and Evaluation

PROCEED: Policy, Regulatory, and Organizational Constructs in Educational and Environmental Development

VAS: Visual Analog Scale

QBPDS: Quebec Back Pain Disability Scale

SF-36: Short Form Health Survey

\section{Decelarations}

\section{Ethics approval and consent to participate}

The Tarbiat Modares University of Ethics Committee for Health Research Ethics (IR. TUM. REC. 2017/545) approved the study. Informed consent will be obtained from all participants.

\section{Consent for publication}

Not applicable

\section{Availability of data and materials}

The data (when ready) will be available from the corresponding author on request. 


\section{Competing interests}

The authors declare that they have no competing interests.

Funding: The study is funded by a grant from Tarbiat Modares University. The role of the funding body in this study, financial assistance was to collect data.

\section{Authors' contributions}

SSK: Collection, analysis, interpretation of data, writing the manuscript, read and approved the final version.

SST: Read and approved the final version.

AM: Analysis, writing the manuscript, read and approved the final version.

\section{Acknowledgements}

The authors will thank the nurses and staff of hospitals of Mazandaran University of Medical Sciences. In particular, educational supervisor, nursing manager, accreditation officer, and nurses in first Phase and nurses participating in the Intervention Phase.

\section{References}

1.John L, Flin R, Mearns K. Bus driver well-being review: 50 years of research. Transportation research part F: traffic psychology and behaviour. 2006;9(2):89-114.

2.Zamanian Z, Salimian Z, Daneshmandi H, AliMohammadi Y. The Reba technique ergonomic assessment of musculoskeletal disorders risk level among midwives of Shiraz State Hospitals. Journal of Urmia Nursing And Midwifery Faculty. 2014;12(1):24-18.

3.Choobineh A, Daneshmandi H, Aghabeigi M, Haghayegh A. Prevalence of musculoskeletal symptoms among employees of Iranian petrochemical industries: October 2009 to December 2012. Int J Occup Environ Med (The IJOEM). 2013;4(4 October):253-195-204.

4.Injuries NO, from Work IRDA. Bureau of Labor Statistics. US Dept of Labor. 2010.

5.Nielens H, Van Zundert J, Mairiaux P, Gailly J, Van Den Hecke N, Mazina D, et al. Chronic low back pain. Good clinical practice (GCP). Belgian Health Care Knowledge Centre (KCE); 2006.

6.Airaksinen O, Brox JI, Cedraschi C, Hildebrandt J, Klaber-Moffett J, Kovacs F, et al. Chapter 4 European guidelines for the management of chronic nonspecific low back pain. European spine journal. 2006;15:s192-s300. 
7.Wieser S, Horisberger B, Schmidhauser S, Eisenring C, Brügger U, Ruckstuhl A, et al. Cost of low back pain in Switzerland in 2005. The European Journal of Health Economics. 2011;12(5):455-67.

8.Katz JN. Lumbar disc disorders and low-back pain: socioeconomic factors and consequences. JBJS. 2006;88:21-4.

9.Waddell G. The Back Pain Revolution. Churchill Livingston: Edinburgh, London, New York. Oxford, Philadelphia, St. Louis, Sydney, Toronto; 2004.

10.Stein N, Brooks K. A fully automated conversational artificial intelligence for weight loss: longitudinal observational study among overweight and obese adults. JMIR diabetes. 2017;2(2):e28.

11. Hoy D, Brooks P, Blyth F, Buchbinder R. The epidemiology of low back pain. Best practice \& research Clinical rheumatology. 2010;24(6):769-81.

12.Rossignol M, Rozenberg S, Leclerc A. Epidemiology of low back pain: what's new? Joint Bone Spine. 2009;76(6):608-13.

13.RAMEZANI BF, NIKBAKHT NA, MOHAMMADPOUR A. Low-back pain prevalence and its risk factors in nurses. 2006.

14.Stubbs D, Buckle P, Hudson M, Rivers P, Worringham C. Back pain in the nursing profession I. Epidemiology and pilot methodology. Ergonomics. 1983;26(8):755-65.

15.Videman T, Nurminen T, Tola S, Kuorinka I, Vanharanta H, Troup J. Low-back pain in nurses and some loading factors of work. Spine. 1984;9(4):400-4.

16.Koepsell TD. Occupational injuries: a study of health care workers at a northwestern health science center and teaching hospital. Workplace Health \& Safety. 1992;40(6):287.

17.Van Hoof W, O'Sullivan K, O'Keeffe M, Verschueren S, O'Sullivan P, Dankaerts W. The efficacy of interventions for low back pain in nurses: A systematic review. International journal of nursing studies. 2018;77:222-31.

18.Yassi A, Lockhart K. Work-relatedness of low back pain in nursing personnel: a systematic review. International journal of occupational and environmental health. 2013;19(3):223-44.

19.Jensen RC. Disabling back injuries among nursing personnel: Research needs justification. Research in nursing \& health. 1987;10(1):29-38.

20.Abolfotouh SM, Mahmoud K, Faraj K, Moammer G, ElSayed A, Abolfotouh MA. Prevalence, consequences and predictors of low back pain among nurses in a tertiary care setting. International orthopaedics. 2015;39(12):2439-49. 
21.Dawson AP, Schluter PJ, Hodges PW, Stewart S, Turner C. Fear of movement, passive coping, manual handling, and severe or radiating pain increase the likelihood of sick leave due to low back pain. PAIN ${ }^{\circ}$. $2011 ; 152(7): 1517-24$.

22.June KJ, Cho SH. Low back pain and work-related factors among nurses in intensive care units. Journal of clinical nursing. 2011;20(3-4):479-87.

23.Soroush A, Shamsi M, Izadi N, Heydarpour B, Samadzadeh S, Shahmohammadi A. Musculoskeletal disorders as common problems among iranian nurses: a systematic review and meta-analysis study. International journal of preventive medicine. 2018;9.

24.Járomi M, Kukla A, Szilágyi B, Simon-Ugron Á, Bobály VK, Makai A, et al. Back School programme for nurses has reduced low back pain levels: A randomised controlled trial. Journal of clinical nursing. 2018;27(5-6):e895-e902.

25.Parreira P, Heymans MW, van Tulder MW, Esmail R, Koes BW, Poquet N, et al. Back schools for chronic non-specific low back pain. Cochrane Database of Systematic Reviews. 2017(8).

26.Burdorf A, Jansen J. Predicting the long term course of low back pain and its consequences for sickness absence and associated work disability. Occupational and environmental medicine. 2006;63(8):522-9.

27.Ando S, Ono Y, Shimaoka M, Hiruta S, Hattori Y, Hori F, et al. Associations of self estimated workloads with musculoskeletal symptoms among hospital nurses. Occupational and environmental medicine. 2000;57(3):211-.

28.Feyer A-M, Herbison P, Williamson AM, de Silva I, Mandryk J, Hendrie L, et al. The role of physical and psychological factors in occupational low back pain: a prospective cohort study. Occupational and environmental medicine. 2000;57(2):116-20.

29.Ferguson SA, Allread WG, Burr DL, Heaney C, Marras WS. Biomechanical, psychosocial and individual risk factors predicting low back functional impairment among furniture distribution employees. Clinical Biomechanics. 2012;27(2):117-23.

30.Adams MA, Mannion AF, Dolan P. Personal risk factors for first-time low back pain. Spine. $1999 ; 24(23): 2497$.

31. Harcombe H, McBride D, Derrett S, Gray A. Physical and psychosocial risk factors for musculoskeletal disorders in New Zealand nurses, postal workers and office workers. Injury Prevention. 2010;16(2):96100.

32.Karlsen B, Oftedal B, Lie SS, Rokne B, Peyrot M, Zoffmann V, et al. Assessment of a web-based Guided Self-Determination intervention for adults with type 2 diabetes in general practice: a study protocol. BMJ open. 2016;6(12):e013026. 
33.Jahangiry L, Shojaeizadeh D, Farhangi MA, Yaseri M, Mohammad K, Najafi M, et al. Interactive webbased lifestyle intervention and metabolic syndrome: findings from the Red Ruby (a randomized controlled trial). Trials. 2015;16(1):418.

34.Garg S, Garg D, Turin TC, Chowdhury MFU. Web-based interventions for chronic back pain: a systematic review. Journal of medical Internet research. 2016;18(7):e139.

35.Korda $\mathrm{H}$, Itani Z. Harnessing social media for health promotion and behavior change. Health promotion practice. 2013;14(1):15-23.

36.Green LW, Marshall W. Kreuter: Health Program Planning: An educational and ecological approach. MC Graw Hill co; 2005.

37.Kamioka H, Okuizumi H, Okada S, Takahashi R, Handa S, Kitayuguchi J, et al. Effectiveness of intervention for low back pain in female caregivers in nursing homes: a pilot trial based on multicenter randomization. Environmental health and preventive medicine. 2011;16(2):97.

38.Svensson AL, Strøyer J, Ebbehøj NE, Schultz-Larsen K, Marott JL, Mortensen OS, et al. Multidimensional intervention and sickness absence in assistant nursing students. Occupational medicine. 2009;59(8):563-9.

39.Ewert T, Limm H, Wessels T, Rackwitz B, von Garnier K, Freumuth R, et al. The comparative effectiveness of a multimodal program versus exercise alone for the secondary prevention of chronic low back pain and disability. PM\&R. 2009;1(9):798-808.

40.Dawson AP, McLennan SN, Schiller SD, Jull GA, Hodges PW, Stewart S. Interventions to prevent back pain and back injury in nurses: a systematic review. Occupational and environmental medicine. 2007;64(10):642-50.

41.Chen $\mathrm{H}-\mathrm{M}$, Wang $\mathrm{H}-\mathrm{H}$, Chen $\mathrm{C}-\mathrm{H}, \mathrm{Hu} \mathrm{H}-\mathrm{M}$. Effectiveness of a stretching exercise program on low back pain and exercise self-efficacy among nurses in Taiwan: a randomized clinical trial. Pain Management Nursing. 2014;15(1):283-91.

42.Evers KE, Prochaska JM, Prochaska JO, Driskell M-M, Cummins CO, Velicer WF. Strengths and weaknesses of health behavior change programs on the Internet. Journal of Health Psychology. 2003;8(1):63-70.

43.Green L, Ottoson J. Public Health Education and Health Promotion. Novick, L.; Morrow, C.; Mays, G., editors. Boston: Jones \& Bartlett Publishers; 2008.

44.Bodian CA, Freedman G, Hossain S, Eisenkraft JB, Beilin Y. The visual analog scale for painClinical significance in postoperative patients. Anesthesiology: The Journal of the American Society of Anesthesiologists. 2001;95(6):1356-61. 
45.Wewers ME, Lowe NK. A critical review of visual analogue scales in the measurement of clinical phenomena. Research in nursing \& health. 1990;13(4):227-36.

46.Sousa FAEF, Pereira LV, Cardoso R, Hortense P. Multidimensional pain evaluation scale. Revista latinoamericana de enfermagem. 2010;18(1):03-10.

47.Mudgalkar N, Bele SD, Valsangkar S, Bodhare TN, Gorre M. Utility of numerical and visual analog scales for evaluating the post-operative pain in rural patients. Indian journal of anaesthesia. 2012;56(6):553.

48.Boonstra AM, Preuper HRS, Reneman MF, Posthumus JB, Stewart RE. Reliability and validity of the visual analogue scale for disability in patients with chronic musculoskeletal pain. International journal of rehabilitation research. 2008;31(2):165-9.

49.Kopec JA, Esdaile JM, Abrahamowicz M, Abenhaim L, Wood-Dauphinee S, Lamping DL, et al. The Quebec Back Pain Disability Scale. Measurement properties. Spine. 1995;20(3):341-52.

50.Mousavi SJ, Parnianpour M, Mehdian H, Montazeri A, Mobini B. The Oswestry disability index, the Roland-Morris disability questionnaire, and the Quebec back pain disability scale: translation and validation studies of the Iranian versions. Spine. 2006;31(14):E454-E9.

51.Framework IC. The MOS 36-item short-form health survey (SF-36). Med Care. 1992;30(6):473-83.

52.Montazeri A, GOSHTASBI A, Vahdaninia M. The short form health survey (SF-36): Translation and validation study of the Iranian version. 2006.

\section{Table 1}

Table 1: The study overview 
Phases Aim Methods Participants

\section{Phase 1}

Situational analysis
Step 1: Identifying predisposing, reinforcing, enabling and environmental factors affecting occupational behaviors

Step 2: Design questionnaire
In-depth interviews Hospital's executive, managerial and policymaking, target groups (Nurses)

Based on Researcher step 1

\section{Phase 2}

Design

interventions

Target group training

Based on

Researcher social media and in-person

\section{Phase 3}

Implementation

Step 1: Transfer educational content to target group

By social

Nurses media and inperson intervention

Step 2: Evaluate the program

Identify the impact of the program in the target group
Questionnaire Nurses and Checklist

Figures 


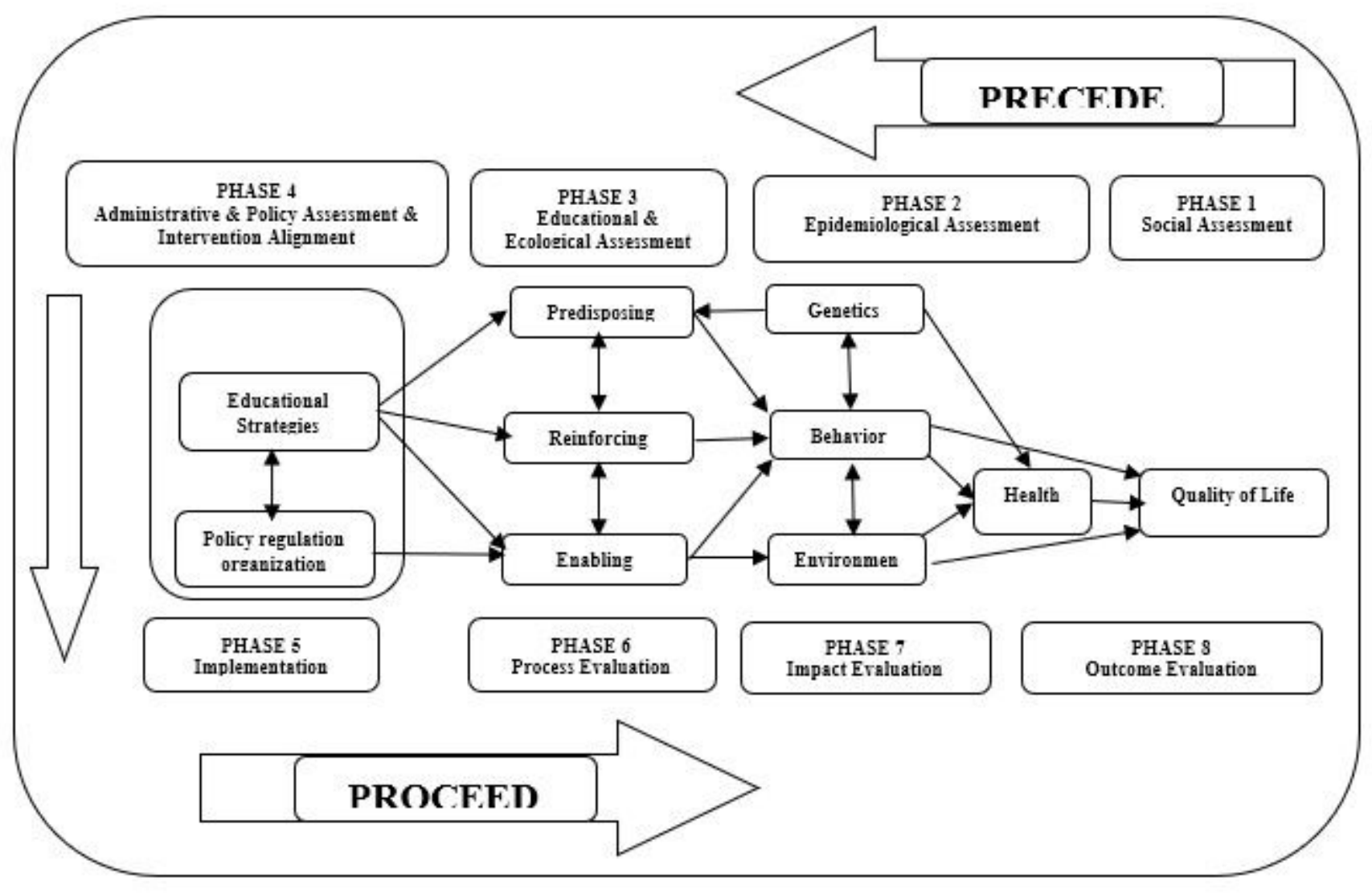

Figure 1

PRECEDE-PROCEED Planning Model 


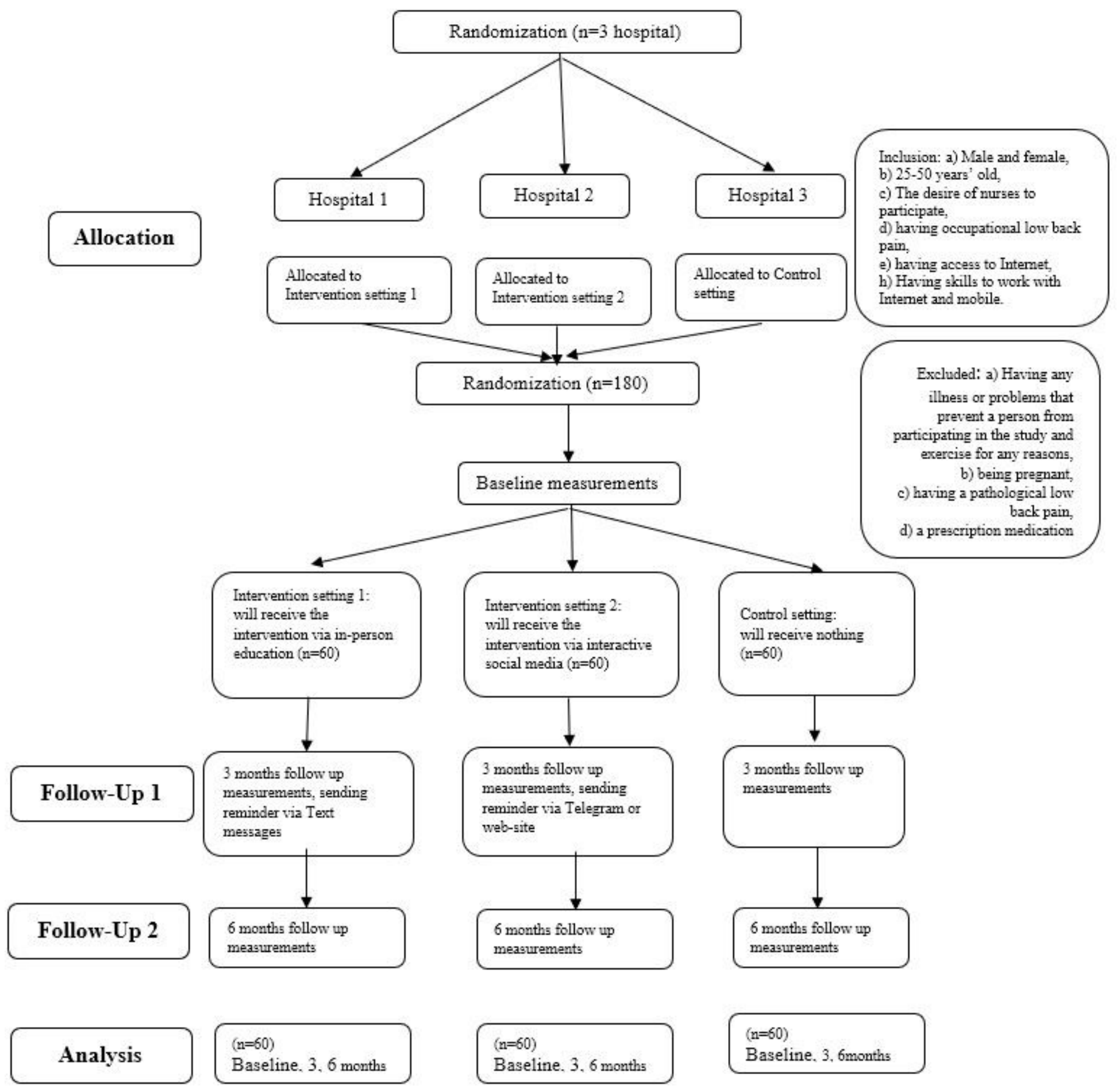

\section{Figure 2}

Flow diagram of the study

\section{Supplementary Files}

This is a list of supplementary files associated with this preprint. Click to download. 
- SPIRITchecklist.doc

Page 19/19 